\title{
QUESTÕES DE TECNICA DE LABORATORIOS (1)
}

\author{
pelo PROF. D. M. GONZALEZ TORRES
}

\section{REAÇÃO DE TAKATA}

Esta reação foi descrita em 1925 por Takata', para o diagnostico diferencial das pneumopatias. Está baseada na propriedade que tem o sôro sanguíneo mediante suas albuminas, de impedir a floculação do óxido de mercurio inestável em status nascendi que se forma pondo em presença uma mistura de cloreto de mercurio e fuchsina em reação debilmente alcalina (sol. de carbonato de sódio).

A presença de corpusculos de alta tensão coloidal (albumina) impede essa floculação, e a mistura guarda nestes casos, a côr vermelha da fuchsina: reação negativa, sôro normal. „Em casos patológicos, devido a uma aumentada labilidade ou transtornos do equilibrio das albuminas, se inhibe esta ação protetora e se produz uma floculação mais ou menos massiva ou uma precipitação, e o liquido que sobrenada permanece claro: reação positiva.

Posteriormente, esta primitiva reação de Takata foi modificada para aplicá-la a outros diagnosticos.

$\mathrm{O}$ mesmo Takata utilizou seu método para o diagnostico das insuficiencias hepaticas, sobretudo nas cirroses, método simplificado mais tarde por UCKO.

ARA praticou uma modificação da reação de Takata para aplicá-la ao estudo do liquor no diagnostico da sifilis nervosa.

\section{REAÇÃO DE TAKATA}

Preparar o reativo de Takata. misturando em partes iguais no momento do uso:

sol. aquosa de sublimado a $0,5 \%$

sol. aquosa de diamante fuchsina $0,02 \%$.

Dispor 10 tubos de ensáio num suporte.

Nos tubos 2 a 10 colocar 2 cc. sol. salina $9^{\circ} / 00$

No tubo 1 colocar 2 cc sôro a estudar.

Do tubo 1 tomar 1cc e levar ao tubo 2 ; misturar,

Do tubo 2 tomar 1cc e levar ao tubo 3; misturar,

(1) Capitulo "Sangue-Serologia" do livro no prelo: Técnica de Laboratorio do prof. Gonzales Torres. $2 .^{\mathrm{a}}$ Ediçāo, aumentada. 
Do tubo 3 tomar 1cc e levar ao túbo 4 ; e assím por diante obtendo-se diluições de $1 / 1$ a $1 / 512$. O 1 cc tomado do tubo 10 jogar fóra.

Ajunatr a todos os tubos 0,25 cc de carbonato de sódio a $10 \%$, agitar, e 0,3 cc do reativo de Takata, misturar, tapar. Praticar a leitura as 24 horas.

Ao ajuntar o reativo de Takata, aparece uma coloração que vai do rosa, nos primeiros tubos, ao violeta, nos ultimos: a reação é negativa.

$A$ reação é positiva quando ha uma floculação e precipitação consecutiva (simpes turbiedade sem floculação ao fim de uma hora: reação negativa).

Si a floculação se produz só nos dois primeiros tubos: a reação é debilmente positiva:

Si a floculação é muito rápida e ha precipitação forte, ficando limpo o liquido que sobrenada: $r$. fortemente posit.

A reação não é especifica da insuficiencia hepatica, porem, conserva um grande valor pela sua notavel frequência nas cirroses (até 93\% segundo os autores), e serve para o diagnostico diferencial entre as afecções hepatobiliares.

Sua intensidade concorda com a gravidade da insuficiencia hepatica. A positividade da reação aparece com o aumento do conteúdo globulinico, ou com a excessiva diminuição do teor albuminico (Schrender. Klin. Woch. N. ${ }^{\circ}$ 18-2-V-36).

É negativa na sifilis e cancer do figado, ictericias infecciosas benignas, no figado cardiaco.

Segundo alguns autores (Hugonot, Schier e Marchall) uma reação positiva de Takata coincide com uma baixa e mesmo uma inversão da relação serina globulina, e frequentemente com uma diminuição das proteinas totais.

\section{REAÇÃO DE TAKATA, MOD. UCKO.}

Dispor quatro tubos secos de hemolise. Colocar em cada um deles 0,20 cc de sôro a examinar; ajuntar:

$0,10-0,15-0,20-0,25 \mathrm{cc}$ respectivamente de sol. aquosa a $0,36 \%$ de carbonato de sódio.

Misturar e ajuntar as mesmas quantidades respectivamente, de sol. aquosa de biclorureto de mercurio a 0,50\%. Agitar. Praticar a leitura 1,30 hora depois.

Reação negativa: não ha precipitação; o sôro permanece opaco ou claro en 3 ou 4 tubos.

Reação positiva: ha precipitação:

fraca, tipo I: ha precipitação nos 3 primeiros tubos positiva, tipo II: ha precipitação nos 4.

forte, tipo III : ha precipitação imediata e massiva nos $4 \mathrm{t}$.

Esta reação tem o mesmo significado que a anterior, com a vantagem de sua maior simplicidade. 


\section{REAÇÃO DE FLOCULAÇÃO DE KAHN}

\section{Material:}

$1^{\circ}$ - Sôro de enfêrmo, sem glóbulos vermelhos, inativado pouco antes da reação, pondo em banho-maria durante meia hora, a $56 .^{\circ}$, logo uma vez mais durante 10 minutos.

2..$^{\circ}$ - Como antígeno, um extrato àlcoólico colesterinado de coração bovino, preparado por E. Behring, e cuja diluição se pratica imediatamente antes do uso, misturando $1 \mathrm{cc}$. do extrato com a quantidade indicada (no rótulo de cada frasco) de sol. fisiológica a 9\%o. A mistura deve ser rápida, aspirando e vertendo várias vezes com a pipeta: deixar, em seguida, 10 minutos à temperatura do Laboratório.

$3 .^{\circ}$ - Usar pipetas e tubos (dếstes, 3 de $10 \mathrm{~mm}$. para cada reação) absolutamente limpos e secos.

Em todas estas reações serológicas de floculação, é conveniente encabeçâr a série com um sôro de reação conhecida negativa e outro de reação positiva, que servirão de test.

Reação:

No tubo 1 pôr $0,05 \mathrm{cc}$. diluição de extrato

No tubo 2 pôr $0,025 \mathrm{cc}$. diluição de extrato

No tubo 3 pôr 0,0125 cc. diluiçãa de extrato.

Ajuntar a cada tubo 0,15 cc. de sôro do enfêrmo.

Agitar 3 minutos no agitador a 275 trepidações por minuto, ou à mão (três agitações de 1 minuto cada uma).

No tubo 4 pôr antígeno e sol. salina: control. antigeno

No tubo 5 pôr 0,1 cc. de sôro e 0,3 de sol. salina: control. sôro,

Deixar 10 minutos na estufa e agitar em seguida 3 minutos.

Ajuntar imediatamente a sol, salina fisiológica:

No tubo $1: 1 \mathrm{cc}$.

No tubo $2: 0,5 \mathrm{cc}$.

No tubo $3: 0,5$ cc.

Agitar um minuto mais, e examinar com o auxílio de uma lupa.

Nos tubos contrôles de antígeno e sôro (tubos 4 e 5 ) não se produz nenhuma floculação, assím como nos casos negativos.

Nos positivos, produz-se uma floculação de intensidade variável, que se nota com os sinais:

$++t+$ fortemente positiva.

$t+t$ positivo.

++ fraco positivo.

+ duvidoso.

Bibriografia, Khan R. L. Uber"meine Flockungsreaktion bei Syphilis. Klin. Wschr. 1928 N. $042,2014$. 


\section{REAÇ̃̃O DE CLARIFICAÇÃO DE MEINICKE}

Material:

(M. K. R. II)

1. ${ }^{\circ}$ Sôro não inativado.

2. ${ }^{\circ}$ - Extrato standardizado para a reação de Meinicke (Original - Standard - Extracts für die M. K. R. II - Adler Apotheke), diluído como mais abaixo se indica.

3. - Solução salina a $3,5 \%$ para a $1 .^{\text {a }}$ série; outra solução salina para a $2 .^{\mathrm{a}}$ série, contendo solução de soda na proporção de 0,01\% (99 cc. de sol. salina do mesmo titulo e 1 cc. de sol. de soda a $1 \%$ ).

\section{Reação:}

Pratica-se a reação em duas séries:

na primeira série, ou principal, usando $0,2 \mathrm{cc}$. de sôro e 0,5 da diluição de extrato em solução salina;

na segunda série, 0,1 cc. de sôro e 0,5 cc. da diluição de extrato em solução salina com soda.

Uma vez dispostos os tubos nos suportes com a quantidade de sôro indicada para cada série, dispõe-se a diluição dos extratos do seguinte modo:

$\left.\begin{array}{l}\text { em um tubo: } 1 \mathrm{cc} \text {. de extrato } \\ \text { em outro tubo: } 10 \mathrm{cc} \text {. de sol. salina }\end{array}\right\}$ para cada série

Levar ambos a banho-maria, durante uns 5 minutos, a $56 .^{\circ}$, em seguida misturar rapidamente o conteúdo de ambos os tubos, passando de um para o outro 2 ou 3 vezes. (Um modo prático é usar um terceiro tubo contendo solução salina e um termômetro, o qual se leva, com os outros dois tubos, a banho-maria, e, quando a coluna mercurial alcança os $56^{\circ}$, é o momento da mistura).

Para a segunda série, emprega-se imediatamente a diluição do extrato; para a primeira série, deixar ainda 2 minutos em banhomaria.

Em ambos os casos, ajuntar 0,5 cc. das diluições a cada tubo, em sua série respectiva. Agitar bastante.

\section{Leitura:}

Pode-se fazer de vários modos, sendo os quatro seguintes os mais usados:

a) Prova de Clarificação.

Deixar os tubos durante 16 a 20 horas à temperatura do Labóratório (uns $20^{\circ}$ ) e examinar: leitosa.

Reação negativa: ambos oș tubos com turvação homogênea,

Positiva fraca: no primeiro tubo, leve sedimentação, e o líquido não é completamente claro (pode-se ver as tráves da janela através do líquido), no $2 .^{\circ}$ tubo: líquido homogeneamente turvo. 
Positiva média: no primeiro tubo, líquido completamente claro; no segundo, turvação homogênea ou líquido não completamente claro. Positiva forte: ambos os tubos com líquido completamente claro.

Positiva muito forte: sòmente no segundo tubo o líquido está mais ou menos completamente claro.

Conservei a mesma nomenclatura indicada for MEINICKE, tal-como vem no prospécto de indicação do uso de seu antígeno. Em muitos Laboratórios da Alemanha, usa-se a seguinte: negativa, posi tiva fraca, positiva, positiva forte.

Em casos de dificuldade para a diferenciaçãao entre uma reação negativa ou uma positiva muito forte, o autor aconselha uma prova de diluição com um sôro conhecido de reação negativa.

Põem-se nos tubos:

0,01 cc. $0,02 \quad 0,04$ cc. de sôro a analisar, e

0,19 cc. 0,18 0,16 cc. de sôro negativo, e

com estas diluições, praticar a reação de MEINICKE como para a primeira série.

O sôro positivo muito forte dá reação positiva em uma ou em todas as diluições. O sôro negativo, em nenhuma.

Êste mesmo método serve para os casos de dificuldades no exame pelos outros procedimentos da mesma reação.

b) Macroscópica Rápida.

Ao terminar a reação, deixar os tubos, durante uma hora e meia à temperatura do Laboratório, e, em seguida, examinar com a lupa como se faz na reação de KAHN:

Negativa: nenhuma floculação nos tubos.

Positiva fraca: sòmente na primeira serie uma floculação fina.

Positiva média: na primeira serie, forte floculação; na segunda, nenhuma "ou fraca floculação.

Positiva forte: em ambas as series, forte floculação. culação.

Positiva muito forte: sòmente na segunda série, forte flo-

c) Microscópica Rápida.

Imediatamente depois de terminada a reação, toma-se de cada tubo, por meio de -pequenas pipetas (tipo Pasteur) (uma para cada tubo), uma gota do líquido e deposita-se sôbre uma lâmina portaobjetos. Colocar ésta numa câmara úmida a $20^{\circ}$, durante 1 hora mais ou menos, e examinar em seguida ao microscópio com fraco aumento (uns 60 d) (Oc. 1 ; obj. $8=0.20$ ).

Negativa: em ambas as gotas, campos iguáis, sem flóculos, muito finamente pontuados."

Positiva: em uma ou ambas as gotas, mais ou menos forte floculação. Anotar os graus de positividade como na reação macroscópica. 


\section{d) Método de Centrifucação. Lectura imediata.}

Para êste método de exame usa-se sòmente uma série de reação, a primeira ou principal (a que se pratica com 0,2 cc de sôro).

Imediatamente depois de terminada a reação, centrifugar os: tubos durante $5-10$ minutos, a 1.500 ou 2.000 voltas por minuto. ( $\mathrm{O}$ tempo de centrifugação e o número de voltas se conhecem em: cada Laboratório e para cada centrifugação logo de provas com sôros de reação conhecida). Decantar com cuidado o líquido mais ou menos claro que sobrenada, deixando no fundo o sedimento azulado. e plano, em fórma de botão. Inverter os tubos com o fundo para. cima e deixá-los no suporte durante 15-30 minutos; examinar a olho nú.

Negativa: o sedimento desliza-se em larga estria branco-azulada.

Positiva fraca: o sedimento distende-se, alarga-se.

Positiva forte: o sedimento apresenta-se como que consistente. inalterável e azul.

\section{REAÇÃO DE MEINICKE DO LIQUOR}

Procede-se como para a primeira série, isto é, com diluição de extrato em solução salina sem soda. Empregam-se 3 tubos ' (no. Diagnostisches Institut de Berlin empregámos 4 tubos) (1).

No $1 .^{\circ}-0,5$ cc liquor e 0,1 diluição de extrato

No $20^{\circ}-0,2$ cc liquor e 0,1 diluição de extrato

No $3 .^{\circ}-0,1$ cc liquor e 0,2 diluição de extrato

No $4 .^{\circ}-0,1$ cc liquor e 0,2 diluição de extrato (1)

A.gitar bem e deixar repousar $16-20$ horas $\hat{a}$ temperatura do Laboratório, em suportes perfurados que permitam a observação. desde baixo.

Para examinar, colocar-se de frente a uma janela, levantar o suporte à altura dos olhos e inclina-lo um pouco de modo que a abertura dos tubos fique em direção â janela e o fundo para o observador. Observar a fórma e a côr do sedimento:

Negativa: nos três tubos, o sedimento, em fórma de botão azul, permanece no centro do fundo.

Positiva: falta o botão azul, em lugar dele, aparece um sedimento. extenso com finas granulações branco-azuladas ocupando toda a ex-tensão do fundo. Pode ser:

Positiva fraca: o botão azul sómente falta no $10^{\circ}$ tubo.

Positiva média: o botão azul falta nos $10^{\circ}-2 .^{\circ}$ tubos.

Positiva forte: o botão azul falta nos três tubos.

Positiva muito forte: só ocasionalmente observada: nos $10^{\circ}$ e $2 .^{\text {on }}$ tubos o botão azul aparece mais ou menos claramente, e, no $3 .^{\circ}$, falta..

Bibliografia. Die zweite Meinicke-Klarungsrealktion auf Syphilis. Separata de Adler- Apoteke. Hagen i. Westfalen. 


\section{MICROREAÇÃO DE CHEDIAK (1)}

É uma reação facil de praticar e que precisa um minimo de material (1 gota de sangue dececado) sendo sua especificidade e sensibilidade igual a das melhores reações conhecidas para a sifilis. Compreende-se que usando uma gota de sangue dececado, o metodo é simples e sobretudo se facilita a remessa do material, e si a isto ajuntamos a rapidez da execução, compreende-se a vantagem dêste metodo.

Material:

1 - 1 gota de sangue dececado e desfibrinado: Por punção do. globulo da orelha ou da polpa do dedo, obtem-se uma grossa gota de sangue sobre una lâmina porta-objeto (não é necessário estar em: jejum); com o ângulo de outra lâmina desfibrina-se a gota, para o que se imprime movimentos circulares e se estende a gota até adquirir o diâmetro de $1 \mathrm{~cm}$. Depois de 30-45 segundos, desta operação, se retira a fibrina, e deixar secar ao ar ou na estufa até $38^{\circ}$ (pode ser secada ao sol ou com uma lâmpada).

A reação deve ser feita até $24: 48$ horas depois, porém, mesmo depois de vários dias ainda se obtem uma alta percentagem de exatidão.

2 - placa de vidro porta-objetos, escavada ou com aneis de parafina ou cerecina.

3 - pipetas de 2 decimos, de $1 \mathrm{cc}$ ao centesimo, de $1,5 \mathrm{cc}$ ao decimo.

4 - solução fresca de cloreto de sodio a $3,5 \%$ (no maximo, de: uma semana, e conservada em frio);

5 - solução de carbonato de sodio a $1 \%$;

6 - antigeno de Meinicke (M. K. R. 11. Adler Apoteke. Hagen) ; sua diluição se pratica no momento do uso com a solução. de cloreto de sódio a 3,5\% a que se ajunta 0,1 cc da solução de carbonato de sodio por cada $10 \mathrm{cc}$ : colocar $1 \mathrm{cc}$ de antigeno num tubo, e $10 \mathrm{cc}$ da solução salina com bicarbonato em outro tubo Colocar ambos durante 5 minutos em banho maria a $56^{\circ}$; misturar o conteudo de ambos os tubos, passando de um para outro duas, três vezes ecolocar de novo durante dois minutos em banho-maria.

Controlar ao microscópio uma gota desta diluição, entre lâmina. e laminula (0c. 10; Obj. menor a seco, 3, ) : deve ver-se um campo. uniforme, finamente ponteado; si não for assim, preparar outra. diluição.

\section{Reação.}

1 - dissolver a gota seca de sangue, ajuntando uma gota $(0,015$ cc segundo Chediak, 0,03 cc segundo Dahr). de solução salina. Com: o angulo de uma lâmina se fazem movimentos circulares para misturar bem, e com o mesmo angulo e enclinando ligeiramente, ao,

(1) T. B. R. (Trockenblutreakton) dos alemães. 
mesmo tempo, a lâmina, transporta-se a gota para uma escavação ou anel de parafina de placa de vidro.

2 - valendo-se de uma pipeta de Klan, ajunta-se 0,03 de antigeno diluido (corresponde a duas gotas com pipeta capilar) misturar bem com o angulo da lamina.

3 - colocar a lamina escavada sobre uma mesa e praticar movimentos circulares durante 3 minutos.

4 - praticar a leitura no microscópio imediatamente (Oc. 10; Obj. menor a seco, 3,). Para evitar que a gota se seque pode-se deixar a placa sobre um papel molhado, dentro de uma caixa de Petri.

Resultados.

Reação negativa: campo uniforme, sem granulos, com finos corpusculos dotados de movimentos browianos;

Reação positiva: grãos negros que tendem a agrupar-se no centro "e que podem ser vistos macroscopicamente, já no fim da reação, quando é fortemente positiva. A positividade tem seus gráus:

Forte: grosos grânulos visíveis a olho nú,

fraca: pequenos grânulos dispersos no campo. reação.

Duvidosa: os grânulos são amarelos e não negros Repetir a

É conveniente deixar as placas numa câmara úmida e fazer outra leitura de control aos 30-60 minutos, quando os fenomenos de flocula*ção coloideantigeno são mais nitidos. E tambem conveniente prati"car as reações encabeçando às séries com um soro conhecidamente positivo (ou soros positivos em diversos gráus) e outro negativo.

A reação de Chediak tem uma sensibilidade comprovada de $90,2 \%$ e uma especificidade absoluta $\left(0,83 \%\right.$ de resultados inespeci- $^{-}$ ficos) e se presta, sobretudo, para o estudo da sifilis larvada ou latente, onde é mais sensivel que a Wassermann e a Meinicke. Na Lues primaria e secundaria a concordância é completa (Wendeborn). Segundo Dahr, na Lues primaria a reação de Chediak é superior à Wassermann e à Meinicke; na Lues secundaria é igual a elas, e na Lues latente é $11 \%$ superior a elas.

Segundo Chediak, em 9.943 casos de Lues estudados por vários autores, foram positivas:

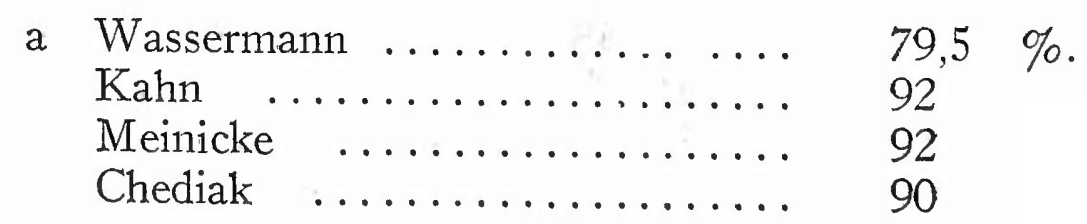

\section{REAÇÃO DE WASSERMANN}

Como diretivas técnicas para a reação de WASERMANN, darei "aquí as que tinhamos em conta pára praticá-la no Diagnostisches Institut de Berlin, por considerar serem as mais práticas e fáceis. 


\section{Material:}

1 - Sôro do enfermo. Obtido o sangue por punção venosa, centrifugar em tubo estéril e levar a banho-maria a $56^{\circ}$ durante meia hora, para inativar. O líquido cefalorraquideano, livre de sangue, não necessita ser inativado.

2 - Solução estéril de cloreto de sódio a 8,5\% 00 .

3 - Suspensão de glóbulos vermelhos de carneiro a $5 \%$. Extrair o sangue da jugular do carneiro, colocar em um frásco com perolas de vidro, agitar para desfibrinar. Colocar em um tubo de centrifugação graduado, e anotar o volume. Centrifugar e decantar, ajuntar solução salina até o volume primitivo, conhecido. Centrifugar, decantar e repetir a mesma operação 2-3 vezes, com o fim de lavar bem as hemácias. Uma vez restabelecido o volume primitivo com solução salina, misturar bem e fazer uma diluição a $5 \%$ na mesma solução salina $(0,1$ de sangue e 1,9 de sol. salina). O sangue de carneiro com perolas de vidro póde ser conservado em geladeira, ou com a adição de formol (1cc para 700cc de sangue) até duas semanas. Centrifugar no dia do uso.

4 - Complemento: sôro de cobáia adulta (mediana, não prenha) obtido por punção do coração, diluido ao décimo com solução salina, preparado uma ou duas horas antes da reação e conservado em geladeira.

5 - Amboceptor ou sôro hemolítico-obtido de coelho imunizado com sangue de adulto. O Instituto Behring fornece o amboceptor de título controlado.

6 - Antígeno: servimo-nos dos seguintes:

a) extrato alcoolico colesterinado de coração humano;

b) idem, idem, bovino;

c) extrato alcoolico de fígado de féto heredoluético.

Todos os três o Instituto Behring fornece com título fixo de diluiç̧ão.

A diluição deve fazer-se para cada extrato, segundo seu título em sol. salina a $8.50^{\circ} /{ }^{00}$.

Pratica-se a reação de WASERMANN em três fases:

1a.) uma reação prévia do amboceptor,

2a.) uma reação ou prova principal e

3a.) uma reação definitiva.

\section{Reação prévia do amboceptor.}

A primeira reação prévia a executar tem por objetivo determinar a diluição do amboceptor a ser usado na reação principal, isto é, determinar até em qué diluiçã̃o do amboceptor se hemolisam completamente as hemácias, em presença do complemento. Para isto pra- 
ticam-se diluições sucessivas de amboceptor, partindo de uma a $1 \%$ e ajuntando-1he o complemento e glóbulos vermelhos de carneiro. Proceder como está indicado no seguinte quadro:

\section{REAÇÃO PREVIA DO AMBOCEPTOR}

diluição do amboceptor

diluição de sangue de carneiro (1)

diluição do complemento

$1: 100$

1: $20=5 \% \backslash \mathrm{em} \mathrm{NaCl}=0,85 \%$

$1: 10=10 \%$

\begin{tabular}{|c|c|c|c|c|c|c|c|c|c|c|c|c|}
\hline & 1: 100 & $1: 200$ & 1: 400 & 1: 800 & 1: 1600 & $1: 3200$ & 1: 6400 & | 1:12800 & & Control & Control & Control \\
\hline $\mathrm{ClNa}$ & & 0.5 & 0.5 & 0.5 & 0.5 & 0.5 & 0.5 & 0.5 & & 1.25 & 1.25 & 1.25 \\
\hline $\begin{array}{l}\text { Ambo- } \\
\text { ceptor }\end{array}$ & $\begin{array}{c}0.5 \mathrm{~d} \\
\mathrm{dil} \\
\mathrm{t}: 100\end{array}$ & $\begin{array}{c}0.5 \mathrm{~d} \rightarrow \\
\mathrm{dil} \\
1: 100\end{array}$ & $\begin{array}{l}0.5 \mathrm{~d} \\
\text { dil. } \\
1: 200\end{array}$ & $\begin{array}{l}0.5 \mathrm{~d} \\
\text { dil. } \\
1: 400\end{array}$ & $\begin{array}{l}0.5 \mathrm{~d} \\
\text { dil. } \\
\text { 1: } 800\end{array}$ & $\begin{array}{c}0.5 \mathrm{~d} \rightarrow \\
\text { dil. } \\
1: 1600\end{array}$ & $\begin{array}{l}0.5 \mathrm{~d} \\
\text { dil. } \\
\text { 1: } 3200\end{array}$ & $\begin{array}{c}0.5 \mathrm{~d} \rightarrow \\
\left.\mathrm{d}_{1}\right]_{0} \\
1: 6400\end{array}$ & 0.5 forte & 0.25 & - & 0.50 \\
\hline $\mathrm{Cl} \mathrm{Na}$ & 1 c.c. & 1 & 1 & 1 & 1 & 1 & 1 & 1 & & - & - & - \\
\hline $\begin{array}{c}\text { Com- } \\
\text { plemt. }\end{array}$ & 0.5 & 0.5 & 6.5 & 0.5 & 0.5 & 0.5 & 0.5 & 0.5 & & 0.5 & 0.5 & - \\
\hline $\begin{array}{l}\text { Sangue } \\
\text { carneíro }\end{array}$ & 0.5 & 0.5 & 0.5 & 0.5 & 0.5 & 0.5 & 0.5 & 0.5 & & 0.5 & 0.5 & 0.5 \\
\hline
\end{tabular}

Deixar 10 minutos no banho maria a 37.0

NOTA:- O sinal $\rightarrow$ coloca dona coluna de Amboceptor indiea que de cada tubo vai retirando-se o necessario para passar no seguinte, e assim sucesivamente.

Como título de diluição do amboceptor tomar-se-á a quarta parte da "diluição correspondente ao último tubo hemolisado. Seja, por exemplo, .o último tubo hemolisado o correspondente à diluição a $1 / 3.200$; o título de diluição do amboceptor para a reação principal será de 1/800 (sempre em solução salina).

Reação ou prova principal.

Tem por finalidade controlar o resultado de uma reação praticada com a diluição do amboceptor, determinada na prova anterior, em presença de sôros de enfermos de reação conhecida (uma fortemente positiva, uma fracamente positiva, outra duvidosa e outra negativa), antígeno, complemento e glóbulos vermelhos de carneiro.

Proceder como se indica no quadro seguinte:

(1) O sangue é retirado do carneiro por punçào venosa 1-2 v. por semana, conservado na geladeira, e centrifugado no dia do uso. 


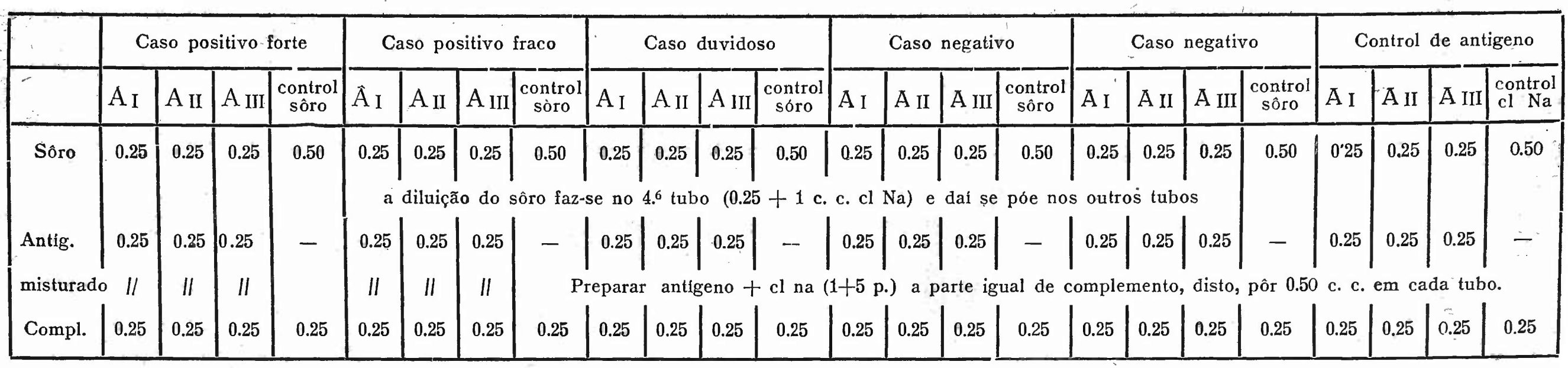

agitar um pouco todos os tubos deixar 30 minutos no banho maria a $37^{\circ}$ ajuntar logo

\begin{tabular}{|c|c|c|c|c|c|c|c|c|c|c|c|c|c|c|c|c|c|c|c|c|c|c|c|c|}
\hline $\begin{array}{l}\text { amboc. } \\
\text { na dose } \\
\text { standard }\end{array}$ & 0.25 & 0.25 & 0.25 & 0.25 & 0.25 & 0.25 & 0.25 & 0.25 & 0.25 & 0.25 & 0.25 & 0.25 & 0.25 & 0.25 & 0.25 & 0.25 & 0.25 & 0.25 & 0.25 & 0.25 & 0.25 & 0.25 & 0.25 & 0.25 \\
\hline misturado & II & II & II & II & II & II & II & II & II & II & II & II & II & II & II & II & II & II & II & II & II & II & II & II \\
\hline $\begin{array}{c}\text { sangue } \\
\text { carneiro }\end{array}$ & 0.25 & 0.25 & 0.25 & 0.25 & 0.25 & 0.25 & 0.25 & 0.25 & 0.25 & 0.25 & 0.25 & 0.25 & 0.25 & 0.25 & 0.25 & 0.25 & 0.25 & 0.25 & 0.25 & 0.25 & 0.25 & 0.25 & 0.25 & 0.25 \\
\hline
\end{tabular}

agitàr um pouco; deixar 10 minutos no bấnho maria a $37^{\circ}$

NOTA - O sinal // que une duas colunas (onde diz: mixturado) indica que sôro e complemento, amboceptor e sangue de carneiro que podem ser misturados antes do uso, e depois deitado nos tubos. 
Si a leitura da reação resulta tal como indica a reação de cada sôro examinado, a diluição usada do amboceptor é boa, e é a indicada para a reação definitiva. Si a leitưra não coincide com o resultado esperado (por exemplo, somente a série de sôro fortemente positivo dá resultado fortemente positivo e os demais negativos, oụ, de um modo geral, a leitura dá um resultado inferior ao esperado), é que a diluição do amboceptor é todavia forte, e se usará uma mais fraca. $\mathrm{Si}$, a contrário, a leitura der um resultado mais forte, mais positivo, que a reação conhecida dos sôros usados, é que a diluição do amboceptor é muito alta.

\section{Reação definitiva.}

Para cada sôro se usam quatro tubos, pois se usam os três antígenos diferentes, citados no começo, e o $4 .^{\circ}$ servirá de contrôle.

Proceder de acôrdo com o quadro seguinte:

\begin{tabular}{|c|c|c|c|c|c|}
\hline Séries & Sôro & \multicolumn{2}{|c|}{$\begin{array}{c}\text { (1) Antigeno } \\
\text { complemento e } \\
\text { sol. salina }\end{array}$} & \multicolumn{2}{|c|}{$\begin{array}{c}\text { Amboceptor }+ \\
\text { hemácias de carneiro }\end{array}$} \\
\hline A I & 0,25 & 0,25 & 0,25 & 0,25 & 0,25 \\
\hline A II & 0,25 & 0,25 & 0,25 & 0,25 & 0,25 \\
\hline A III & 0,25 & 0,25 & 0,25 & 0,25 & 0,25 \\
\hline A IV & 0,50 & - & $\begin{array}{c}0,25 \\
(2)\end{array}$ & 0,25 & 0,25 \\
\hline
\end{tabular}

(1) Tomar 1 parte de antígeno (por ex. 0,5 cc), mais 5 partes de solução salina 2,5 cc.) mais 6 partes de complemento ( 3 cc.); desta mistura, deitar 0,5 cc. em cada tubo.

(2) Só complemento, sem sol. salina nem antígeno.

\section{REAÇÃO DE WASSERMANN NO LIQUOR}

Procede-se em tudo como se fosse para a reação no sôro, com a diferença de que o liquor não é inativado e se usam 3 diluições para cada liquor, como' indica o quadro seguinte:

\begin{tabular}{|c|c|c|c|c|}
\hline AntIg. I & $\begin{array}{l}\text { liquor } \\
\text { sol. salina }\end{array}$ & $\stackrel{0,25}{--}$ & $\begin{array}{r}0,125 \\
-\quad 0,125\end{array}$ & $\begin{array}{l}0.06 \\
0,19\end{array}$ \\
\hline Anttg. II & $\begin{array}{l}\text { liquor } \\
\text { sol. salina }\end{array}$ & $\begin{array}{r}0,25 \\
--\end{array}$ & $\begin{array}{l}0,125 \\
0,125\end{array}$ & $\begin{array}{l}0,06 \\
0,19\end{array}$ \\
\hline Antig. III & $\begin{array}{l}\text { liquor } \\
\text { sol. salina }\end{array}$ & 0,25 & $\begin{array}{l}0,125 \\
0,125\end{array}$ & $\begin{array}{l}0,06 \\
0,19\end{array}$ \\
\hline Contrôle & $\begin{array}{l}\text { liquor } \\
\text { sol. salina }\end{array}$ & 0,50 & $\begin{array}{l}0,125 \\
0.125\end{array}$ & $\begin{array}{l}0,125 \\
0,375\end{array}$ \\
\hline
\end{tabular}




\section{Leitura da reação de WASSERMANN.} hemólise.

Os'tubos contrôles (tubos 4) devem apresentar-se em completa

Negativa: hemólise nos três tubọs, como no contrôle.

Positiva: não ha hemólise, o líquido se apresenta turvo, como. que leitoso, opaco, em grau variável, que anotaremos em 3 graus, segundo sua opacidade crescente.

+ Fraca: gl. vermelhos em grande parte hemolisados', liquido. apenas ligeiramente opaco.

++ Média: hemácias em parte hemolisadas, líquido sobrenadante de côr rosa.

+++ Forte: gl. vermelhos sem hemólise.

\pm Duvidosa: reação que póde apresentar-se : o líquido, quasi completamente hemolisado, aparece como que velado.

\section{POSSIBILIDADES DA LEITURA E RESULTADOS A DAR}

A leitura de cada tubo nem sempre é igual nos tres, do qual resulta certa dificuldade no resultado a dar; no quadro seguinte estão dispostos as possibilidades de leitura em cada tubo e os resultados que se costumam dar e a equivalencia na nomenclatura aconselhada a.. seguir pela Sociedade das Nações (Comité de Higiené).

\begin{tabular}{|c|c|c|c|c|c|}
\hline Leitura & Tubo 1 & Tubô 2 & Tubó 3 & $\begin{array}{l}\text { Resultado } \\
\text { a dar }\end{array}$ & $\begin{array}{l}\text { Soc. das } \\
\text { nações }\end{array}$ \\
\hline \multirow{6}{*}{$\therefore$} & - & $\begin{array}{l}- \\
\pm\end{array}$ & $\begin{array}{l}- \\
+ \\
+\end{array}$ & $\frac{-}{\text { Negativa }-}$ & Negativa - \\
\hline & - & $\overline{ \pm}$ & $\begin{array}{l}++ \\
++\end{array}$ & Duvidoso \pm & Duvidosa \pm \\
\hline & $\begin{array}{l}- \\
- \\
- \\
-\end{array}$ & $\begin{array}{l}- \\
- \\
\pm \\
+ \\
+\end{array}$ & $\begin{array}{c}+++ \\
++++ \\
+t+t \\
++ \\
+++\end{array}$ & Fraca posit. + & \multirow{2}{*}{ Positiva + } \\
\hline & $\begin{array}{l}- \\
- \\
+\end{array}$ & $\begin{array}{c}t \\
++t \\
++t \\
+t\end{array}$ & $\begin{array}{c}++++ \\
+++ \\
++++ \\
+++\end{array}$ & Positiva ++ & \\
\hline & $\begin{array}{l}- \\
+ \\
++ \\
\end{array}$ & $\begin{array}{l}t+t+ \\
+++ \\
++++\end{array}$ & $\begin{array}{l}+t+t \\
+t+t \\
+t+t\end{array}$ & \multirow{2}{*}{$\begin{array}{c}++t \\
\text { Forte positiva } \\
++++\end{array}$} & \multirow{2}{*}{$\underset{\text { positiva }}{\text { Forte }}++$} \\
\hline & $\begin{array}{l}+t+ \\
+++t\end{array}$ & $\begin{array}{l}+++t \\
++++\end{array}$ & $\begin{array}{l}++++ \\
++++\end{array}$ & & \\
\hline
\end{tabular}

Bibliografia. Anleitung fur die Ausfuhrung der WaR. Sonderabdruck N.o 25 zu dem: Ministerialblatt f. die preussische Verwaltung. 1934, N.o 44.

Rapport de la conference de Laboratoire sur le serodiagnostic de la Syphilis.

Convoqué a Montevideo. Série de Publicat de la Sac. des Nations. 1931, III. 4. 


\section{UT NOVO ASTRO do quimioterapia antibateriona}



A THIAZAMIDA (SULFATIAZOL), denvado tiazólico da sulfanilámida, veiu resolver o problema até há pouco considerado insolúvel däs

\section{INFECÇŌES ESTAFILOCÓCICÁS}

A taxa de mortalidade pelas septicemias estafilocócicas foi consideravelmente diminuida com $\circ$ advento da THIAZAMIDA, que também se revelou altamente eficaz contra

\section{INFECCÒES GONOCÓCICAS INFECCOEES PNEUMOCOCICAS}

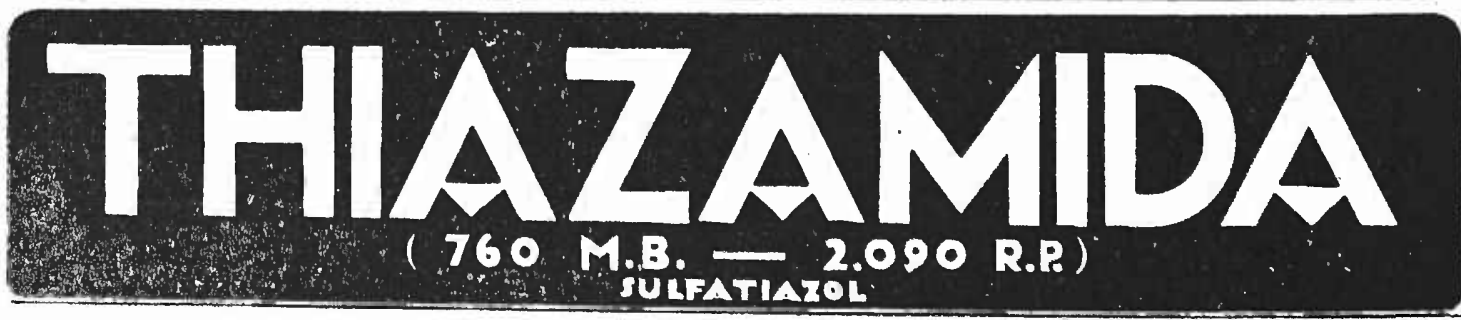

coraespondencia: Rhodio c postalzom.spaulo 


\section{ORIENTAÇÕES PARA O USO}

Esta é uma cópia digital de um documento (ou parte dele) que pertence a um dos acervos que fazem parte da Biblioteca Digital de Obras Raras e Especiais da USP. Trata-se de uma referência a um documento original. Neste sentido, procuramos manter a integridade e a autenticidade da fonte, não realizando alterações no ambiente digital - com exceção de ajustes de cor, contraste e definição.

1. Você apenas deve utilizar esta obra para fins não comerciais. Os livros, textos e imagens que publicamos na Biblioteca Digital de Obras Raras e Especiais da USP são de domínio público, no entanto, é proibido o uso comercial das nossas imagens.

2. Atribuição. Quando utilizar este documento em outro contexto, você deve dar crédito ao autor (ou autores), à Biblioteca Digital de Obras Raras e Especiais da USP e ao acervo original, da forma como aparece na ficha catalográfica (metadados) do repositório digital. Pedimos que você não republique este conteúdo na rede mundial de computadores (internet) sem a nossa expressa autorização.

3. Direitos do autor. No Brasil, os direitos do autor são regulados pela Lei n. ${ }^{\circ}$ 9.610, de 19 de Fevereiro de 1998. Os direitos do autor estão também respaldados na Convenção de Berna, de 1971. Sabemos das dificuldades existentes para a verificação se uma obra realmente encontra-se em domínio público. Neste sentido, se você acreditar que algum documento publicado na Biblioteca Digital de Obras Raras e Especiais da USP esteja violando direitos autorais de tradução, versão, exibição, reprodução ou quaisquer outros, solicitamos que nos informe imediatamente (dtsibi@usp.br). 